\title{
(息)
}

Citation:

Malik, M and Grogan, S and Cole, J and Gough, B (2019) Men's reflections on their body image at different life stages: A thematic analysis of interview accounts from middleaged men. Journal of Health Psychology. p. 1359105319871640. ISSN 1461-7277 DOI: https://doi.org/10.1177/1359105319871640

Link to Leeds Beckett Repository record:

https://eprints.leedsbeckett.ac.uk/id/eprint/6143/

Document Version:

Article (Accepted Version)

The aim of the Leeds Beckett Repository is to provide open access to our research, as required by funder policies and permitted by publishers and copyright law.

The Leeds Beckett repository holds a wide range of publications, each of which has been checked for copyright and the relevant embargo period has been applied by the Research Services team.

We operate on a standard take-down policy. If you are the author or publisher of an output and you would like it removed from the repository, please contact us and we will investigate on a case-by-case basis.

Each thesis in the repository has been cleared where necessary by the author for third party copyright. If you would like a thesis to be removed from the repository or believe there is an issue with copyright, please contact us on openaccess@leedsbeckett.ac.uk and we will investigate on a case-by-case basis. 
Men's reflections on their body image at different life stages: A thematic analysis of interview accounts from middle-aged men

${ }^{1}$ Mohammed Malik, ${ }^{1}$ Sarah Grogan, ${ }^{1}$ Jennifer Cole, and ${ }^{2}$ Brendan Gough

${ }^{1}$ Department of Psychology, Manchester Metropolitan University, UK

${ }^{2}$ School of Social Sciences, Leeds Beckett University, UK

RUNNING HEAD: MEN REFLECTING ON THEIR BODY IMAGE

For correspondence:

Professor Sarah Grogan

Psychology

Manchester

Brooks Building

Birley Campus

53 Bonsall Street

Manchester

United Kingdom

M15 6GX

s.grogan@mmu.ac.uk

+441612472504

Accepted Journal of Health Psychology $31^{\text {st }}$ July 2019 


\begin{abstract}
This study investigates how men's body image develops over time. 14 men aged between 45 and 67 years completed in-depth interviews where they discussed their body image since childhood, prompted in some cases by photographs of themselves at different ages that they brought to the interviews. Transcripts were analysed using inductive thematic analysis. From the participants' accounts it was evident that body concerns did not steadily improve or worsen, but waxed and waned over time. Results are discussed in relation to understanding changing body concerns in men's lives, and the implications of these for future research and practice.
\end{abstract}

Key words: body image; interviews; middle-aged men; reflecting; aging; life stages. 


\section{Men's reflections on their body image at different life stages: A thematic analysis of interview accounts from middle-aged men}

Body image has generally been conceptualised as a feminine issue (Hargreaves and Tiggemann, 2006) and women's body image has garnered more attention than male body image. Since the 1980s, male body image research has developed substantially and now includes coverage of men's body image at different age points (Gough et al., 2016; Kenny et al., 2017; Tatangelo and Ricciardelli, 2017; Whitaker et al., 2019). Research with men has indicated that men's body dissatisfaction is widespread to the extent that feeling dissatisfied with the body is regarded as normal (Griffiths et al., 2018). This is unsurprising given that the cultural ideal for men has become increasingly muscular and leaner - and difficult to obtain (Diedrichs and Lee, 2010). Societal ideals for men's bodies have become less hairy over time (Terry and Braun, 2016), and being tall (Griffiths et al., 2017) and having a large penis (Flowers et al., 2013; Hall, 2015) have been associated with body satisfaction. Short height has been linked to impaired quality of life (Griffiths et al., 2017), and underestimation of penis size associated with small penis syndrome and avoidance of sex (Wylie and Eardley, 2006).

As a construct, men's body image has been discussed in terms of how the body performs, as well as how it appears (Drummond, 2019; Leichty et al., 2014). The former has been a salient theme especially in research with preadolescent boys and older men, highlighting performance as important in the display and maintenance of masculine identities (Tatangelo and Ricciardelli, 2013).

Though men have been found to downplay their body dissatisfaction (Jankowski et al., 2018), this does not minimise the threats that body dissatisfaction poses for men's physical and psychological well-being. Male body dissatisfaction has been associated with uptake of multiple health-risk behaviours including consumption of appearance and performance enhancing drugs (APEDs; Hildebrandt et al., 2012); and anabolic-androgenic steroids 
(Greenway and Price, 2018), both of which have been associated with serious long-term negative health consequences (Grogan 2006). To approximate the hairless ideal, men have engaged in depilation practices, which can damage healthy skin (McCreary et al., 2007); and concerns surrounding penis size have led to risky surgical and nonsurgical procedures (Flowers et al., 2013; Hall, 2015). In response to some of the stated health risks above, body image prevention programmes have been designed and delivered to both boys and men to help promote a more positive body image (Brown et al., 2017; Jankowski et al., 2017; McCabe et al., 2010; Stanford and McCabe, 2005).

While progress has been made in terms of identifying and targeting areas contributing to negative body image in boys and young men, research examining body image in men aged over 30 years is rare (McGuinness and Taylor, 2016), though we know that they may experience an upsurge in body dissatisfaction, body shame and disordered eating due to changes in body shape and body fat (Boisvert and Harrell, 2012) and due to decline in sexual functioning (Lodge and Umberson, 2013). On the other hand, Mangweth-Matzek et al., (2016) found that only $6.8 \%$ of middle-aged men reported eating disorder symptoms; and Mulgrew and Craggs (2017) found that middle-aged men were less susceptible to idealized portrayals of the male body compared to younger men, showing that findings relating to middle-aged men's body image are inconclusive. Most of the studies on middle-aged men's body image are also quantitative in design (Mangweth-Matzek et al., 2016; McGuiness and Taylor, 2016; Mulgrew and Craggs, 2017). Given that research on middle-aged men's body image is still sparse, it is important and appropriate to gain deeper understandings of the issues related to middle-aged men's body image.

While existing work has produced interesting data on body image in men and boys of different ages, most previous work is cross-sectional, partly due to the obvious cost and practical challenges in conducting longitudinal work following boys as they age. Belonging to 
different historical cohorts may have an important influence on men's body image due to historical changes in body ideals (Fawkner, 2012; McCabe, 2012). The current study offers a unique alternative to cross-sectional studies as it focuses on middle aged men who reflect on their body image at different ages, reducing the impact of generational differences. Furthermore, the study also addresses the paucity of research on body image in men over the age of 30 years (Slevin and Linneman, 2010; Vas et al., 2016).

\section{The Current Study}

The aim of the current study was to analyse middle-aged men's accounts in relation to their previous and current body image. The research question for the present study was as follows: What body image issues and body-related activities do men report at different life stages?

\section{Method}

\section{Design}

\section{In-depth Interviews Using Photo Prompts}

In-depth interviews were chosen to collect personal accounts from men by asking questions based on topics highlighted in the body image literature (e.g. peer influence, muscularity, weight management etc.). Participants were also asked to bring in old photographs of themselves from different stages in their lives to serve as prompts for reflection (six of 14 participants brought photographs).

\section{Recruitment}

As participants were required to reflect on a range of earlier life stages, along with discussing their current body image, we aimed to recruit men in their 40s-60s. It was believed that men of this age-range could successfully reflect on several developmental stages. Additionally, they could also shed light on how they feel about their bodies as middle-aged men. Participants for the current study were recruited via a voluntary sampling method. Details of the study were 
advertised in a range of different settings around [City]. Opportunities also arose from out of [City] through snowball sampling, which were considered.

\section{Participants}

14 men of various ethnic and social backgrounds aged between 45 and 67 years took part in the current study. Pseudonyms were used to maintain anonymity.

\section{Procedure}

Ethical approval was obtained from the faculty academic ethics committee at Manchester Metropolitan University. Upon successful recruitment of participants, informed consent was obtained from participants, and dates and times for the interviews were finalised. Interviews were conducted by the first author at various locations where participants were happy to disclose information. While the interviewer had a topic list to guide his interviews, questions were asked in an open and flexible manner, allowing participants to guide the researcher through their own narratives. Once the interview was completed, participants were debriefed and thanked for their contributions.

\section{Data Analysis}

Interviews ranged from 60 to 90 minutes. They were transcribed verbatim and analysed using inductive thematic analysis (Braun and Clark, 2006). Inductive thematic analysis is a branch of thematic analysis wherein researchers aim to analyse their data without letting their preconceptions about the subject area influence their analysis (Frith and Gleeson, 2004). This type of analysis felt most fitting given the apparent shortage of research on middle-aged men's body image. The first author conducted the analysis for the current study based on the six steps established by Braun and Clarke (2006). All themes were agreed by all four authors.

\section{Results and Discussion}

It was evident that body concerns were not something which gradually improved or worsened for respondents but were something which waxed and waned over time. Besides age, major life 
transitions (such as marriage and divorce) were found to have a significant influence over the way men felt about their bodies in later stages of their lives. Eight themes were identified for men when reflecting on their body image at different time points (see Table 1). Pseudonyms are used below to protect the identity of participants, and quotes are reported verbatim.

\section{INSERT TABLE 1 ABOUT HERE}

\section{Preadolescence}

\section{Theme 1: No Real Body Image Concerns}

When discussing awareness of their bodies in preadolescence, eight out of 15 participants indicated that they did not have any real concerns about their bodies during their preadolescence. However, there was variation in the way that participants chose to communicate this information to the researcher. For instance, Ben articulated his unconcern about his body as 'at 8, fairly un-self-conscious'. Jack reported 'Umm, probably not even aware of my body to be honest'. From these two extracts, it is clear that both these participants were not really conscious of how their bodies looked during their preadolescent years, thus did not feel any apprehension towards the way that their bodies appeared to others during this time. Like Ben and Jack, Sid's response 'I don't think-I don't think I really understood' could also be construed as him not being appearance-focused during his preadolescence.

While Ben, Jack and Sid indicated that they were not really conscious of their bodies during their preadolescent years, Tom and Derek chose to express their unconcern for their bodies differently. For example, Tom said 'I think as a youngster, not bothered about it at all, appearance that is...', and Derek 'no, I don 't think I was even bothered about it'. It was clear that neither of these two participants recalled feeling worried or upset about the way that their bodies appeared at that age.

When questioned about his weight and whether it had any impact over his body image, Noah replied 'No, no I was just a normal kid', perhaps implying that 'normal' boys are not (or 
at least not expected to be) concerned with the way that their bodies appear during this stage. Similarly, Ahmed could possibly be seen as confirming this observation when saying 'I never thought about it that way as a child'. The notion that boys do not have any real body image concerns during this phase conflicts with a range of existing literature. For example, in a study conducted by Ricciardelli et al., (2006), preadolescent boys were found to display body image problems comparable to those of men and adolescent boys. Furthermore, in another study (Dunn et al., 2010), nearly 50\% of preadolescent boys between the ages of eight and 11 displayed a preference to be thinner. However, the studies mentioned above represent preadolescent boys of today, while the findings from the current study tell a story about the preadolescent boys of the past, where the appearance of the male body was perhaps not such as focus as it is today (Farquhar and Wasylkiw, 2007).

Theme 2: 'Focus on Sport'

From participants' accounts, their interest in sports kept these men distracted from focusing on aesthetical aspects of their bodies. This theme was reflected in seven of the 14 interviews. For example, Ahmed argued that he did not really get an opportunity to be worried about the way that he looked due to being largely involved with sporting activities:

Ahmed: $\quad$ No, I never had a concern, like I said, I was into sports so much, I never got a chance to be to physically worried about my look-the way I look. I looked fine, naturally.

Similarly, Ken expressed how he was more aware about playing football with his friends and less concerned about how his body appeared while reflecting on his preadolescent phase. Furthermore, he mentioned how not developing an interest in girls at this point served as a buffer from developing body image concerns.

Ken: $\quad$ And at that stage [preadolescence] I wasn't really interested in girls. I was playing with my mates, football, y'know all that kind of thing, I 
don't think I was that self-conscious at that stage because I wasn't really bothered about girls.

This focus on sport mirrors that seen in other research focusing on preadolescent boys' body image (e.g. Tatangelo and Ricciardelli, 2013).

\section{Adolescence and Young Adulthood}

The narrative changed when participants had reached their adolescence and young adulthood phase. By this point, participants reported that they had become fully aware of their bodies, providing reasons for why they felt an upsurge in body concerns and began to engage in appearance fixing behaviours during these developmental stages.

Theme 3: Interpersonal Attraction and Bodily Awareness

One of the causes that respondents ascribed to sudden body awareness was a growing interest in members of the opposite sex.

This trend was identified in Jack's interview (see below):

Interviewer: When would you say that you DID become aware of your body then?

Jack: $\quad$ Probably at 14 or 15 when-when I noticed girls really... when I got to about fourteen or fifteen though, erm, I suddenly thought. I looked around and thought, ooh, you know, there are some interesting things out there and umm, what does it take to get closer to those really, and so that-that impacted on-on-on how I looked-I did start to look at myself, caught myself in the mirror more...I was just looking at that point to make myself more attractive really to-to girls

From the extract above, it is clear that adolescence was not just a period where Jack became aware of his body, but it was also a time marked by his interest in finding out what he could do in order to make himself more desirable to members of the opposite sex. 
Like Jack, David also reported that he became conscious of his body as a result of noticing members of the opposite sex. Furthermore, he described how he wanted 'to look his best', and how he began to start paying attention to his hair due to this realisation:

David: $\quad$ Erm, probably about 12-13. When you start noticing girls, and you know, you're wanting to look your best, and, you know, you start doing your hair you know...

Only one previous study was located where adolescent boys' desire to impress girls was associated with the development of body concerns and the onset of appearance-fixing behaviours (Hargreaves and Tiggemann, 2006). Other research studies have produced contradictory outcomes; for example, Grogan and Richards' (2002) interviews with heterosexual men indicated that though men were aware of women's preferences regarding their body tone and musculature, this did not encourage them to change their bodies, an observation supported by other authors (Fawkner, 2012; Hargreaves and Tiggemann, 2006).

Ken and Tom add to this narrative around girls:

Ken: $\quad$...underlying everything I think it is about attracting a mate, male or female, doesn't matter what your orientation, personally I believe that.

While what Ken has said here could just be an alternative way of confirming the observations above, the fact that Ken suggested that it was fundamentally "all about attracting a mate" shows that he considered the body to play a significant role in establishing long-term bonds. Similarly, Tom makes use of the term 'relationships', which could be interpreted as implying the same thing.

Tom: $\quad$ Probably it's got to be, when-when y'know when you first sort of become interested in err in relationships and you know the opposite sex and so on, erm, around 14.

Theme 4: Body Type and Social Acceptance 
Besides attracting women, participants reported that another factor compelling them to think about their bodies during their adolescence and emerging adulthood was their desire to be part of certain social groups. Moreover, they highlighted how acceptance by social groups was influenced by the types of bodies they possessed. Men during these two stages also wanted to be highly popular with members of the same gender, supporting Ricciardelli (2012). For example, according to Sid, in order to be selected for a football or cricket team, one needed to look a certain way otherwise they were not welcomed to be part of it:

Sid: If you can't do certain things, you don't look or dressed a certain way, then you're not in

Derek, like Sid, was also found discussing body type and social acceptance from his social circle:

Derek: $\quad$...you don't want to be like that guy who is left behind every time that nobody wants to pick on for their football group team. You want to be the first guy that everyone picks, you know

Interviewer: oh so you are saying that the way you look determined-had a link with whether or not you could join a specific football team do you think?

Derek: $\quad y e a h$, well I mean not for a football team, but to go out, we used to go into the city you know to socialise, wanna look like-they want...you know what I mean. Teenagers are teenagers, you know, you go back to any era and you'll find people will want to be in the coolest group or whatever it may be, you know we all want to be in the popular group

As can be seen in the extract above, Derek describes how sport teams had preferences for certain body types and how, as an adolescent, he desired to attain the body that would allow him entry into such teams. Besides football team selection, Derek discussed how socialising in general also made him conscious of his body. This mirrors research which suggests that boys 
who endorse a muscular physique that demonstrates strength and athletic ability have a better chance of being perceived as popular by their peers (Ricciardelli, 2012).

Adolescents' desires to be popular are understandable considering that adolescence has been identified as a phase in an individual's life where feeling accepted and supported by peers is momentous (Bukowski et al., 1993). When Derek stated that he did not want to be 'the guy who was left behind', he may have felt (at the time) that had he not conformed to social expectations of how his body should look, he could have potentially faced a number of negative social consequences, including the risk of being unpopular and rejected by his peers (Wang et al., 2006).

Similarly, adult men in Grogan and Richards (2002) focus groups were found making associations between appearing attractive and feeling 'confident' and 'powerful' in social situations. Grogan and Richards (2002) added that men's desire to appear lean and muscular was mainly due to aesthetic reasons (over health and fitness), and that this was largely related to the notion of social acceptance. Interestingly, Derek's quote ends with him mentioning how, irrespective of whichever era one belongs to, one will always want to affiliate with the 'coolest' and most 'popular' group. This is an interesting point considering that it is possibly showing similarities between different generations of adolescent boys and young adult men.

\section{Early Midlife}

Body concerns appeared to become subservient for some of the participants as they entered early midlife, seemingly in line with another change in men's priorities.

\section{Theme 5: Family Life and Body (In)attention}

When men were questioned about their body image during this period, a number of participants highlighted how it became very difficult to give their bodies any adequate attention during this time, providing similar reasons. For example, Derek expressed that time spent with his children was the primary reason why he was unable to give his body appropriate consideration: 
Derek: $\quad$ Once you have kids, it's very-it's harder to find the time to do those things, to counteract it, to go out and exercise

Furthermore, Derek went on to communicate how working long hours became an essential requirement to make ends meet for his family and how this resulted in having less time for himself.

Like Derek, financial stability for the family also appeared to be the prime concern and obstacle for Sid as a middle-aged man. Sid too found himself prioritising his duties as a father over his desires to accomplish his ideal body. This is demonstrated in the following extract:

Sid: $\quad$ Paying a mortgage was crucial, putting food on the table was crucial, having a roof over your head and paying your bills was critical. Having a gym membership from 50 to 70 pound a month, not good Theme 6: Divorce and Body Panic

Another important factor which appeared to have an impact on the way some male participants felt about their bodies during the early midlife period was finding themselves alone. For two of the participants, being divorced appeared to be the primary reason why they began to feel concerned about their bodies once again:

Jack: $\quad$ You suddenly look at yourself and think I'm divorced and err you think, I wouldn't really fancy me either, if I saw me now, so, I'll do something about it.

It seems from this quote that when Jack was still in a relationship with his former wife, he was fairly relaxed about his body, though this suddenly changed when he was no longer in a relationship. When Jack says 'I wouldn't really fancy me either' and 'I'll do something about that', he suggests that at that point he had a desire to be with someone again and believed the only way to make that possible was to alter his physical appearance. 
Like Jack, Ken also communicated how his divorce caused a resurgence of body image concerns within him and made him feel conscious and 'vulnerable' about his body above other things:

Ken: When you walk in, the first thing they see is YOU. They see your body, they see your hair your face. And that's the first impression they have of you. And when you feel vulnerable and kind of lost, err, you become a bit more self-conscious. Am I massively fat? Or extremely skinny? Or got lots of spots? Or losing all my hair?

This all comes into focus. Because, because you feel vulnerable.

It is clear from Jack and Ken's narratives that marital dissolution left both participants thinking about their bodies. Nonetheless, more work is required to explore the effects of divorce on male body image.

\section{Later Midlife: Current Evaluations of the Body}

Theme 7: Concerns Regarding Body Functionality

When participants were asked to comment on their current body image, the men had a tendency to talk about functional and performance-related aspects of their bodies, including health, as suggested by other researchers (e.g. Grogan, 2017; Hall, 2014; Leichty et al., 2014). For instance, David discussed what his body could no longer do, as a result of his weight-gain, highlighting the importance of (compromised) functionality of the body:

David: I think it is slowing me down

The men discussed functional aspects of weight gain and its physical costs in later-life; for example, Jack expressed how he feared weight-gain could deny him medical attention in the future:

Jack: If I get very big and I need an operation, the surgeon won't operate, 'cause they cannot operate on very fat people. 
Similarly, Bradley's body concerns also appeared to focus on (impaired) bodily functions. For example:

Bradley: $\quad$...erm abdominal fat is quite erm, expensive to carry around because it weighs on my bladder and-and in my age it means that erm, I can have what they call urge inconsistence.

None of the participants in the present study mentioned appearance-related concerns resulting from their weight-gain, contradicting findings from more recent qualitative research on older obese men who expressed heightened body consciousness and body dissatisfaction as a result of their overweight status (Gough et al., 2016). Considering the inconsistency of findings in this area, it is important that more research is done that covers both functional and aesthetic concerns.

\section{Theme 8: Body Acceptance}

Another theme from this stage related to body acceptance (Tylka, 2011). While body acceptance has not been written about extensively within male body image research up until now, there are a couple of studies which link directly to the results of the present study. For example, in a study by Slevin and Linnemann (2010) it was highlighted that men became more accepting of themselves as they age- For example, in the quote below, Jack says:

Jack: $\quad$... I think you do get a little more comfortable within yourself This statement can be interpreted as being suggestive of body acceptance; Jack might have been implying that individuals become accustomed to their bodies and ultimately learn to accept them. Similarly, when Sid was asked whether he thought appearance-related pressures intensified with age, his initial response was:

Sid: $\quad$ No I don't think they do. I think, as-as you get older, you just turn around and say NO. 
However, Sid subsequently went on to voice how age enforced a kind of honesty with himself about his appearance. He could never appear like his 20 and 30-year-old counterparts and described this as a 'fantasy', an 'illusion' and 'not the real world'. For Sid, body acceptance stems from the inability to reverse aging. This research outcome supports findings from Leichty et al., (2014) wherein older Canadian men, between the ages of 60 and 70, expressed a contentment with age-related body changes, considering that these changes were 'beyond their control'.

Craig also reported being content with his body as a middle-aged man as well as implying that body image concerns are not of upmost importance compared to other things. For example:

Craig: $\quad$ I'm happy with my body image, because I think I understand perhaps its place in the general scheme of things.

Like Jack, Sid and Craig, Jeff also reported being content with his body. Despite wanting to lose weight, Jeff goes on to explain in the quote below that he would not engage in any bodychanging practices which would get in the way of his eating pleasures. For example:

Jeff: $\quad$ I'm content with what I am. You know, size wise, you know its not what I-if I could I'd like to lose two stones, but I wouldn't want it to spoil what I do, what I eat, what I drink, you know.

It appears that men primarily come to accept their bodies in later midlife due to the understanding that aging is an inevitable process; thus, concerns relating to appearance become less substantial and men become more comfortable with their bodies. Though there may be aspects of men's bodies which they wish were different, based on these findings, appearance concerns at this age may not be extensive or important enough for men to bring about changes to their bodies, or to come in the way of their daily pleasures.

\section{Conclusion}


It was clear from respondents' narratives that the presence and absence of body concerns was largely regulated by certain goals participants pursued at different time points. For example, playing sports appeared to be the main objective for participants when reflecting back on their body image in the preadolescent phase. During this period, an awareness of body aesthetics seemed to be largely absent from participants' lives. In adolescence and young adulthood, body image concerns came to the fore as a result of wanting to pursue romantic relationships and affiliating with popular social groups. During early midlife, body image became subservient as participants found themselves reassessing their priorities as fathers; though marital disruption caused some middle-aged men to renegotiate the role their bodies play in their lives. Ultimately, men in later midlife reported that they were no longer preoccupied with what their body looked like, rather their concerns were shifted to how healthy their bodies were. Moreover, men in later midlife reported body acceptance.

\section{Strengths}

One of the main strengths of this study is that it has generated in-depth data on how men feel about their bodies during their middle years; accessing a cohort whose body image has not been explored as extensively as other male cohorts (McGuiness \& Taylor, 2016). This study has presented distinctive themes which have not been elaborated in previous male body image research, for instance men feeling apprehensive about their bodies post-divorce and the role that family plays in men's body maintenance during midlife. A further strength of the current study is that it focused on men's accounts of changes over time rather than focusing on men at different age groups who may have differed on body ideals, enabling a life span perspective.

\section{Limitations and Implications for Future Research and Practice}

Men were not questioned about their sexual preferences at the time of the interviews, and this was an oversight since disparities between gay and heterosexual men's body image have been 
cited within body image literature (Lodge and Umberson, 2013), so future work should gain an indication of men's sexual orientations. Health psychologists working with men in relation to promoting behaviours such as healthy eating and exercise in particular need to be aware that body dissatisfaction may link with key life stages and life events, so may vary during men's life courses. 


\section{References}

Boisvert JA and Harrell WA (2012) Ethnicity and spirituality as risk factors for eating disorder symptomatology in men. International Journal of Men's Health 11(1): 3662.

Braun V and Clark V (2006) Using thematic analysis in psychology. Qualitative Research in Psychology 3(2): 77-101.

Brown TA, Forney KJ, Pinner, D, et al. (2017) A randomized controlled trial of The Body Project: More Than Muscles for men with body dissatisfaction. International Journal of Eating Disorders 50(8): 873-883.

Bukowski WM, Hoza B and Boivin, M (1993) Popularity, friendship, and emotional adjustment during early adolescence. New Directions for Child \& Adolescent Development 60: 23-37.

Cawley J, Joyner K and Sobal J (2006) Size matters: The influence of adolescents' weight and height on dating and sex. Rationality \& Society 18(1): 67-94.

Connell RW and Messersschmidt JW (2005) Hegemonic masculinity: rethinking the concept. Gender and Society 19(6): 829-859.

Diedrichs PC and Lee C (2010) GI Joe or average Joe? The impact of average-size and muscular male fashion models on men's and women's body image and advertisement effectiveness. Body Image, 7(3): 218-226.

Drummond MJN (2003) Retired men retired bodies. International Journal of Men's Health 2(3): 183-199.

Drummond, MJN (2019) Boys' bodies, sport, health and physical activity. London: Palgrave MacMillan. 
Dunn J, Lewis V and Patrick S (2010) The idealization of thin figures and appearance concerns in middle-school children. Journal of Applied Biobehavioural Research, 15(3): 134-143.

Farquhar JC and Wasylkiw L (2007) Media images of men: Trends and consequences of body conceptualization. Psychology of Men \& Masculinity 8(3): 145-160.

Fawkner HJ (2012) Body image development - adult men. In Cash TF (eds) Encyclopedia of body image and human appearance. Amsterdam: Elsevier, pp. 194-200.

Flowers P, Langdridge D, Gough B et al. (2013) On the biomedicalization of the penis: the commodification of function and aesthetics. International Journal of Men's Health 12(2): 121-137.

Frith H and Gleeson K (2004) Clothing and embodiment: men managing body and appearance. Psychology of Men and Masculinity 5(1): 40-48.

Gough B, Seymour-Smith S and Matthews CR (2016) Body dissatisfaction, appearance investment, and wellbeing: How older obese men orient to "aesthetic health". Psychology of Men and Masculinity, 17(1): 84-91.

Greenway CW and Price C (2018) A qualitative study of the motivations for anabolicandrogenic steroid use: The role of muscle dysmorphia and self-esteem in long-term users. Performance Enhancement \& Health 6(1): 12-20.

Griffiths S, Murray SB, Medeiros A et al. (2017) The tall and short of it: An investigation of height ideals, height preferences, height dissatisfaction, heightism, and height-related quality of life impairment among sexual minority men. Body Image 23: 146-154.

Grogan, S. (2017). Understanding body dissatisfaction in men, women and children (third edition). New York: Routledge

Grogan S and Richards H (2002) Body image: Focus groups with boys and men. Men and Masculinities, 4(3): 219-232. 
Grogan S, Shepherd S, Evans R, et al. (2006) Experiences of anabolic steroid use: In-depth interviews with men and women body builders. Journal of Health Psychology 11(6): 845-856.

Hall M (2015) 'When there's no underbush the tree looks taller': a discourse analysis of men's online groin shaving talk. Sexualities, 18(8): 997-1017.

Hall, M (2014). Metrosexual masculinities. London: Palgrave MacMillan.

Hargreaves DA and Tiggemann M (2006) "Body image is for girls": A qualitative study of boys' body image. Journal of Health Psychology 11(4): 567-576.

Hildebrandt T, Harty S and Langenbucher JW (2012). Fitness supplements as a gateway substance for anabolic-androgenic steroid use. Psychology of Addictive Behaviors, 26(4), 955-962. doi: 10.1037/a0027877.

Jankowksi GS, Gough B, Fawkner H, et al. (2018) Young men's minimisation of their body dissatisfaction. Psychology \& Health 33(11): 1343-1363.

Kenny U, O’Malley-Keighran M-P, Molcho, M, et al. (2017) Peer influences on adolescent body image: Friends or foes? Journal of Adolescent Research 32(6): 768-799.

Leichty, T, Ribeiro NF, Sveinson K, et al. (2014). "It's about what I can do with my body": Body image and embodied experiences of aging among older Canadian men. International Journal of Men's Health 13(1): 3-21.

Lodge AC and Umberson D (2013) Age and embodied masculinities: Midlife gay and heterosexual men talk about their bodies. Journal of Aging Studies, 27(3): 225-232.

Mangweth-Matzek B, Kummer KK and Pope HG (2016) Eating disorder symptoms in middle-aged and older men. International Journal of Eating Disorders 49(10): 953957.

McCabe MP (2012) Body image development - boy children. In Cash TF (eds) Encyclopedia of body image and human appearance. Amsterdam: Elsevier, pp. 207-211. 
McCabe MP, Ricciardelli LA and Karantzas G (2010) Impact of a healthy body image program among adolescent boys on body image, negative affect, and body change strategies. Body Image 7(2): 117-123.

McGuinness S and Taylor JE (2016) Understanding body dissatisfaction and disordered eating in midlife adults. New Zealand Journal of Psychology 45(1): 4-12.

Mulgrew KE and Cragg DNC (2017) Age differences in body image responses to idealized male figures in music television. Journal of Health Psychology 22(6): 811-822.

Ricciardelli LA (2012) Body image development - adolescent boys. In: Cash TF (eds) Encyclopedia of body image and human appearance. Amsterdam: Elsevier, pp. 180186.

Ricciardelli LA and McCabe MP (2009) Extreme weight change behviours: are overweight and normal weight adolescents different, and does this vary over time? European Eating Disorders Review 17(4): 301-314.

Ricciardelli LA, McCabe MP and Banfield S. (2000). Body image and body change methods in adolescent boys: Roles of parents, friends and the media. Journal of Psychosomatic Research 49(3), 189-197.

Ricciardelli LA, McCabe MP, Lillis J, et al. (2006) A longitudinal investigation of the development of weight and muscle concerns among preadolescent boys. Journal of Youth \& Adolescence 35(2): 177-187.

Slevin KF and Linneman, TJ (2010) Old gay men's bodies and masculinities. Men and Masculinities 12(4): 483-507.

Tatangelo GL and Ricciardelli LA (2013) A qualitative study of preadolescent boys' and girls' body image: Gendered ideals and sociocultural influences. Body Image 10(4): 591-598. 
Tatangelo GL and Ricciardelli LA (2017) Children's body image and social comparisons with peers and the media. Journal of Health Psychology 22(6): 776-787.

Tylka TL (2011) Positive psychology perspectives on body image. In Cash TF and Smolak L (eds) Body image: A handbook of science, practice, and prevention. New York: Guilford, pp.56-64.

Vas S, Forshaw M and Grogan S (2016) Men's experiences of middle-age: An Interpretative Phenomenological Analysis. NORMA: International Journal for Masculinity Studies 11(2): 71-88.

Wang SS, Houshyar S and Prinstein MJ (2006) Adolescent girls' and boys' weight-related health behaviours and cognitions: associations with reputation-and preference-based peer status. Health Psychology 25(5), 658-663.

Whitaker C, Gough B, Fawkner H and Deighton-Smith N (2019) Young men's body dissatisfaction: A qualitative analysis of anonymous online accounts. Journal of Health Psychology.

Wylie KR and Eardley I (2006) Penile size and the 'small penis syndrome'. BJU International 99(6): 1449-1455. 
Table 1

Themes associated with different developmental stages

\begin{tabular}{|l|l|}
\hline Age Group & Theme \\
\hline Preadolescence (approx. 8-11 years) & Theme 1: No Real Body Image Concerns \\
Theme 2: Focus on Sport \\
\hline Adulthood (approx.12-29 years) & Theme 3: Interpersonal Attraction and \\
& Bodily Awareness \\
\hline Reflections on Early Midlife (approx. 30-45 & Theme 4: Body Type and Social \\
years) & (In)Attention \\
\hline Reflections on Later Midlife (over 45 years) & Theme 7: Concerns Regarding Body \\
& Functionality \\
& Theme 8: Body Acceptance \\
\hline
\end{tabular}

